\title{
Interpersonal discrimination and markers of adiposity in longitudinal studies: a systematic review
}

Carla de O. Bernardo ${ }^{1}$

João L. Bastos ${ }^{1}$

David A. González-Chica ${ }^{2}$

Marco A. Peres ${ }^{3}$

Yin C. Paradies ${ }^{4}$

1 Post-Graduate Program in Public Health, Federal University of Santa Catarina, Florianópolis, Santa Catarina, Brazil;

2 Discipline of General Practice, School of Medicine, The University of Adelaide, Adelaide, South Australia, Australia;

${ }^{3}$ Australian Research Centre for Population Oral Health, School of Dentistry, The University of Adelaide, Adelaide, South Australia, Australia;

${ }^{4}$ Alfred Deakin Institute for Citizenship and Globalisation, Deakin University, Melbourne, Victoria, Australia.

Keywords: Discrimination, Adiposity, Inequities, Obesity

Running title: Discrimination and markers of adiposity

Acknowledgements: Higher Education Personnel Improvement Coordination (CAPES) for the PhD scholarship.

Address of corresponding author:

Carla de Oliveira Bernardo

This is the author manuscript accepted for publication and has undergone full peer review but has not been through the copyediting, typesetting, pagination and proofreading process, which may lead to differences between this version and the Version of Record. Please cite this article as doi: 10.1111/obr.12564

This article is protected by copyright. All rights reserved. 
Departamento de Saúde Pública, Centro de Ciências da Saúde, 3o andar Universidade Federal de Santa Catarina, Campus Trindade, Florianópolis, SC, Brasil. CEP: 88040-900Ｅ-mail address: carlabernardoo@gmail.com The authors declare no potential conflict of interest.

\section{Abstract}

While the impact of interpersonal discrimination on mental health is well established, its effects on physical health outcomes have not been fully elucidated. This study systematically reviewed the literature on the prospective association between interpersonal discrimination and markers of adiposity. Medline, Web of Science, Scopus, PsycInfo, SciELO, LILACS, Google Scholar, Capes/Brazil and ProQuest databases were used to retrieve relevant information in November 2016. The results from the 10 studies that met the inclusion criteria support an association between interpersonal self-reported discrimination and the outcomes. In general, the most consistent findings were for weight and Body Mass Index (BMI) among women, i.e., high levels of self-reported discrimination were related to increased weight and BMI. Waist circumference (WC) showed a similar pattern of association with discrimination, in a positive direction, but an inverted U-shaped association was also found. Despite a few inverse associations between discrimination and markers of adiposity, none of the associations were statistically significant. Overall, markers of adiposity were consistently associated with discrimination, mainly through direct and nonlinear associations. This review provides evidence that self-reported discrimination can play an important role in weight, BMI and WC changes.

This article is protected by copyright. All rights reserved. 


\section{Introduction}

Discrimination has been described in societies for centuries, intertwined with social hierarchies and ideas of superiority/inferiority (1). It can be characterized as differential and unfair treatment of members of particular social groups, which includes actions that promote an unjust disadvantage for its victims or unfairly benefit dominant social categories (2). It can also occur at multiple levels, such as the interpersonal (interactions between individuals), institutional (i.e., policies that promote unfair restrictions to certain population segments) or internalised (i.e., individuals of minority groups internalise and accept negative messages and stereotypes about their own group), as well as in different life domains such as family, school, university, workplace, or neighbourhood $(2,3)$. Discriminatory experiences can be caused by multiple motives, including skin colour/race, social class, gender, age, sexual orientation, and physical disability, among others (4).

Despite the well-established link between discrimination and poor mental health (5-9), its effects on physical health are still controversial and have been addressed in numerous studies (10-18) and literature reviews (4-7, 9, 19-30). However, the majority of the reviews published so far focus almost exclusively on one specific type of discrimination $(5,7,9,20-23,27,30)$, particularly racial discrimination, and mainly on blood pressure and cardiovascular disease (20, 22, 24-29).

According to a review published in 2006 (5), four original studies, published in three different articles, investigated the association between internalised racism and markers of adiposity in 2004; however, none of these studies assessed interpersonal discrimination (31-33). Of note, only one of these publications showed a positive association between internalised racism and increased body mass index (BMI) (31). On the other hand, three of them found internalised racism to be positively associated with waist circumference (WC) among women (31-33). One of these studies (31) also reported that the odds of abdominal obesity, a waist to hip ratio (WHR) $>0.80$, was 2.3 
times greater for women with high internalized racism than for those with low internalized racism. Another study (33) found that internalised racism was directly correlated with WC among girls $(r=0.244 ; \mathrm{p}=0.018)$ but not among boys. The authors suggested that, based on previous studies on anthropometric measures and psychosocial factors $(34,35)$, the effects of a social stressor such as discrimination on metabolism could be more pronounced among women than men.

An ensuing study updated the abovementioned review, adding articles published between 2005 and 2007 (7), and identified an additional study on the relationship between racial discrimination and abdominal obesity (WHR >0.80) (13). In contrast to previous studies that addressed abdominal obesity as the outcome, the results showed an inverse association with discrimination. Another review published in the same year (23) identified one additional article investigating markers of adiposity as an outcome (36). The results of this cross-sectional study indicated that weight- and race-based discrimination were directly associated with increased BMI and obesity, while other types of discrimination showed no association with these outcomes (36). This finding may support the notion that weight-based discrimination can be even more pervasive and prevalent than other types of discrimination, since unfair treatment due to one's weight remains socially acceptable and there are no laws that prohibit this type of behaviour (37). Increasing estimates of weight discrimination observed in a 10-year study support this claim (38). A recent meta-analysis on the prevalence of weight discrimination in persons with obesity found that this type of discrimination is more frequent among women and individuals with more extreme obesity (BMI>35 $\mathrm{kgm}^{2}$ ) (30).

Some authors propose that, regardless of the type of discrimination, chronic discriminatory experiences may act as a psychosocial stressor for victims, inducing deregulation of the hypothalamic-pituitary-adrenocortical axis and triggering exaggerated physiological responses over time which can increase vulnerability to physical problems. According to this mechanism, stress activates the central nervous 
system and hypothalamic-pituitary-adrenal axis, which, via corticotropin-releasing hormone, induces adrenocorticotropic hormone production and, thus, cortisol secretion. In turn, cortisol activates lipoprotein lipase, which promotes the accumulation of excess body fat $(39,40)$. Furthermore, previous studies found that discrimination may affect self-control, potentially promoting deleterious health choices, including increased intake of unhealthy food (41-44). According to researchers in this field, eating problems may occur as strategies to cope with discrimination, given that food may be used to supress or soothe emotions such as anger, depression and anxiety (45-47).

It should be emphasized, though, that recent articles have been published on the relationship between discrimination and markers of adiposity, but these articles have not yet been included in the most recent literature reviews. Summarisation and discussion of these results are important for policies and initiatives aimed at addressing both adiposity and perceived discrimination. Many recent cross-sectional studies have shown an association between discrimination and physical health (48-53), but little is known about the temporal ordering of this association because longitudinal studies on the topic are scarce. A review of the literature addressing this issue will help to elucidate this relationship, which is still considered inconsistent by researchers in the field (5-7, 9, 19$23,26,27)$. Furthermore, different forms of discrimination should be investigated, as their complex interactions may have stronger impacts on health, above and beyond each form of discrimination in isolation (54).

This review aims to assess whether the positive association between interpersonal discriminatory experiences and markers of adiposity, such as weight, WC, abdominal obesity and WHR, is consistent among longitudinal studies.

\section{Methods}

\section{Literature search}


The literature search was carried out in English and Portuguese, due to the language capacities of the team, and was designed to locate published and unpublished studies (grey literature). The following databases and electronic collections were searched: Medline (via Pubmed), Web of Science, Scopus, PsycInfo, Sociological Abstracts, Scientific Electronic Library Online (SciELO), Latin American and Caribbean Literature on Health Sciences (LILACS), Google Scholar, Coordination for the Improvement of Higher Level Personnel (Capes/Brazil) and ProQuest, the last two for dissertations/theses. In addition, all reference lists were manually searched for relevant studies, and personal contacts through electronic messages with experts were made in the context of this work.

\section{Search strategy}

This review focused on the relationship between discrimination and markers of adiposity. Interpersonal discrimination was the exposure, regardless of the reason, and all timeframes were included. We formulated the search query, including controlled vocabulary, at the highest level of each tree hierarchy when a database thesaurus was available. In cases in which the controlled term could not be identified, the authors discussed the best alternatives. The following discrimination-related terms were used in the search queries: prejudice, social discrimination, social stigma, racism, ageism, classism, sexism, heterosexism, weight bias, homophobia, xenophobia, unfair treatment, stereotyping, race relations, interpersonal discrimination, and perceived discrimination. These terms were included in the search queries together with each of the following outcome terms: body weight, body weights and measures, body composition, nutritional status, body mass index, obesity, overweight, weight gain, waist circumference, waist to hip ratio, waist to height ratio, body weight changes, abdominal fat, and anthropometry. All terms were translated into Portuguese for use in the Brazilian bibliographic databases. No limits (e.g., study design, age, and sex) were used during the first phase of the literature search. Relatively sensitive search strategies were developed to retrieve 
all potentially eligible studies, including those in which discrimination or markers of adiposity were not analysed as an exposure or an outcome, respectively, but as covariates in the statistical models. The systematic review followed the reporting guidelines and criteria set in Preferred Reporting Items for Systematic Reviews (PRISMA) (55).

\section{Data extraction}

We used EndNote X7 (56) to import the results from each of the selected bibliographic databases. Duplicates were removed, and two reviewers independently screened all titles and, when necessary, the abstracts to assess the eligibility of each publication. We included epidemiologic studies that examined a relationship between a self-reported measure of interpersonal discrimination and markers of adiposity. Given that we were interested in associations stemming from cohort (longitudinal) investigations, crosssectional studies were excluded. We also excluded studies on markers of adiposity in different social groups with no evaluation of discriminatory experiences, as well as studies assessing internalised racism, group racism, bias or bullying. However, studies in which other similar constructs were conceptualized as a surrogate for interpersonal discrimination were included in the present review $(57,58)$. For instance, one study assessing bullying fulfilled the eligibility criteria for the present review because it assessed bullying based on socially stigmatized identities or characteristics, i.e., weightand race-based bullying (58). Although both bullying and interpersonal discrimination may involve an intention to harm, interpersonal discrimination is more clearly connected to power imbalances among various social categories, i.e., hegemonic and subordinate groups in society. While bullying may be based on, for instance, the fact that someone wears glasses, interpersonal discrimination necessarily stems from people's identification with major categories of difference (axes of inequality), such as gender, race, class, and sexual orientation. Therefore, original studies addressing other constructs that were operationalised as a specific form of discrimination were included in this review. 
The next phase was full text examination, and the articles underwent data extraction by the first author and another reviewer. Any discrepancies regarding the inclusion of articles between reviewers were resolved by consensus and/or by discussion with a third reviewer. Data from the included studies were extracted into an Excel spreadsheet by the first author (COB), and doubts were checked by another reviewer (JLB). All inconsistencies were resolved by consensus and/or by a third reviewer. The following data were extracted: authors; year of publication; journal of publication; sampling procedure (probabilistic or convenience); sample characteristics, including sample size, study location (country/nation) and participants' demographic characteristics (age and gender); exposure measure(s), including instrument names and author(s); outcome measure(s), including how it was collected (self-reported or directly measured).

\section{Statistical analyses}

The results were presented in contingency tables and included all statistically significant and non-significant associations, as well as the direction of association (direct or positive - includes positive linear associations between discrimination and the outcomes; inverse or negative - includes inverse associations, for instance, higher levels of discrimination with lower BMI or lower WC; non-linear - includes associations in which the association between discrimination and nutritional health was not directly proportional). Thus, the proportion of statistically significant $(\mathrm{p}<0.05)$ associations was calculated using all associations found in the 10 studies. Whenever different types of discrimination were assessed, all of them were included. Associations adjusted for confounding variables in statistical models or related techniques were included when possible.

\section{Results}

A total of 10 studies met the inclusion criteria (57-66), after the exclusion of 31 papers with a cross-sectional design. Sixteen papers assessed other levels of discrimination, 
such as internalised racism and institutional racism, two papers assessed only change in the prevalence of discrimination among different BMI groups, six papers had insufficient data, and four abstracts or congress presentations were included (Figure 1). Table 1 displays the characteristics of the reviewed studies. All of the 10 papers were published in the last seven years, and 80\% were published from 2013 onwards. The majority used probabilistic samples (70\%), with more than 1,000 participants (90\%), and was carried out in the US (80\%). Only two papers were conducted in different countries, England and Sweden. Most of the 10 studies included adults/elderly (90\%) and samples of both sexes $(80 \%)$. None of the studies was carried out with men exclusively. Seventy percent of the studies had a follow-up period of at least four year, and two studies were carried out for more than 10 years. Table 2 shows the types of discrimination assessed and the instruments used to assess these experiences, as well as the markers of adiposity and how they were measured. The most frequent types of discrimination were racial and weight discrimination. Thirty percent of studies assessed more than one type of discrimination. While most studies assessed discriminatory experiences in different domains of life, one paper assessed health care discrimination only.

Self-reported interpersonal discrimination was measured through previously developed instruments, including the Everyday Discrimination Scale (EDS) in $60 \%$ of the studies and the Experiences of Discrimination (EOD) in 10\% of the studies. A few studies used instruments designed specifically for their studies $(20 \%)$ or a single item (10\%). The number of items used in the papers ranged from one to nine, but at least $50 \%$ of the studies used six or more items. The exposure timeframe was not clear or not specified in $90 \%$ of the selected studies, while only one (10\%) study investigated discriminatory experiences in the past year. Two studies (20\%) also assessed lifetime discrimination in addition to everyday discrimination.

Despite that the search strategy included a range of markers of adiposity, only data on weight, BMI and WC were found within the included papers. Among the studies, $50 \%$ 
assessed BMI change as the outcome. The same percentage investigated WC change, while only $20 \%$ assessed weight change over a period of time. Most studies (70\%) assessed markers of adiposity via self-reports, and one study assessed both self-reported and directly measured anthropometric data. Two studies (20\%) evaluated not only changes in nutritional markers but also in discriminatory experiences over time. The authors hypothesized that groups with higher levels of discrimination in both waves would experience larger changes in the outcome.

Associations between discrimination and markers of adiposity

Table 3 presents all of the associations found in the adjusted analyses of studies on selfreported discrimination and markers of adiposity included in this review. The outcomes are shown alongside information on the direction of association and the number of statistically significant associations. Weight and BMI change were directly associated with discrimination; all associations with the former were statistically significant, while 21 out of 24 associations were significant for the latter outcome. WC change was also directly associated with discrimination, but only in 8 out of 18 cases were the associations statistically significant. On the other hand, a statistically significant inverted U-shaped association was also found between WC change and discrimination. The outcomes "become obese" and "remain obese" showed mainly direct associations with discrimination, but statistical significance was reached for only 9 out of 13 associations and 2 out of 7 associations, respectively. There were several inverse associations between discrimination and markers of adiposity, but none of them was statistically significant. Overall, the outcomes assessed were consistently related to discrimination, mainly through direct and nonlinear associations.

Most of the studies adjusted for a range of confounders, including socioeconomic and demographic factors such as age (adjusted for in all studies), education (9 studies), sex/gender ( 8 studies, the other 2 studies included women only), racial/ethnic affiliation (5 studies), income/socioeconomic status (5 studies), geographic area of residence (3 studies), parity (3 studies) and marital/partner status (2 studies). Risk factors were also 
used to adjust the analyses, such as BMI at baseline (6 studies), physical activity (5 studies), smoking (3 studies), drinking (3 studies), food intake (3 studies) and stressful events (3 studies).

Among the associations found in all studies, only one showed a nonlinear shape (inverted U-shape), and 43 out of the 65 positive associations were statistically significant. No negative association was statistically significant.

Types of discrimination and anthropometric markers

Among the 10 studies included in this review, a range of types of discrimination were assessed and related to different outcomes. Because the results vary between the sexes and the type of discrimination experienced, we showed the associations separately by groups (Table 4). All analyses assessing weight change as the outcome were positive and statistically significant regardless of the type of discrimination, while $\mathrm{WC}$ change showed different relationships between sexes. The associations between racial discrimination and WC change were observed only among women and were mainly positive and nonlinear. Considering discrimination with a non-specific motivation, associations were found among women and men; however, the proportion of statistically significant results was higher among the former (5 out of 6 vs. 1 out of 4 associations). The pattern was similar when BMI change was the outcome and racial discrimination was the exploratory variable; a statistically significant association was found in women and among the total sample (50\% of associations was significant) but not in men. On the other hand, weight discrimination had $100 \%$ statistically significant associations both in women and men. The last two outcomes assessed by the selected studies showed a similar pattern of results. While discrimination based on ancestry, age, sex, physical disability, appearance and sexual orientation were not significantly related with becoming or remaining obese, weight discrimination showed a high proportion of significant direct associations with both outcomes (100\% and 67\%, respectively). Nevertheless, racial discrimination was associated with the incidence of obesity (all associations were significant). 


\section{Discussion}

The results of this review suggest that there is an association between self-reported discrimination and markers of adiposity, whose shape is mainly linear, i.e., high levels of discrimination were associated with higher levels of adiposity. The most consistent findings in this body of knowledge to date have been for weight and BMI change among women (high levels of self-reported discrimination were related to higher weight and BMI change). Inverse associations were also found, although none was statistically significant.

This review found that a substantial number of people reported different forms of discrimination, and these experiences were related to higher levels of adiposity. However, comparisons should be made with caution due to heterogeneity among the studies. The exposure timeframe was not specified in most studies, the anthropometric data were self-reported among $70 \%$ of the studies, and the subgroups assessed in the papers varied in relation to skin colour, BMI subclass and sex. The sample size was large in all of the studies included in this review, which demonstrates the researchers' effort to produce accurate results.

Studies on racial discrimination have dominated the literature on discrimination and obesity for a long time, but the results of this review found that other types of discrimination have been investigated, specifically weight discrimination. Thirty percent of studies were listed under the racial discrimination category and $30 \%$ under the weight discrimination, while another $10 \%$ studied both of them. We also observed a growing interest in assessing other forms of discrimination, as well as how multiple types of discrimination can combine and affect markers of adiposity. The hypothesis that social stressors that are uncontrollable and unpredictable, such as discrimination, are particularly harmful to physical health increases the need for policies and initiatives aimed at reducing the prevalence of this phenomena (37). 
A relevant finding of this review is that approximately $30 \%$ of the studies measured discrimination using a single item or an instrument with no previous psychometric assessment. Such practice hampers comparisons across studies and limits the knowledge about discrimination in different countries, and the information about prevalence, associations and specificities of the phenomena become incomparable. The use of instruments with no equivalent items affects the understanding of how discrimination manifests itself in different societies. Furthermore, each instrument has a specific exposure timeframe, which further complicates the interpretation of findings from original studies. For instance, some authors contend that we need to capture exposure to discrimination over the course of life (67) to assess its effects on health outcomes; however, there are recall problems when the period under analysis is longer. In spite of these limitations, the results support associations between interpersonal discrimination and higher levels of adiposity regardless of how discrimination was measured, which suggests that the associations are not dependent on any type of measure.

To compare results and strengthen the knowledge about discrimination, future research should use instruments with good psychometric properties that have equivalent and comparable versions according to varied social and historical contexts. Thus, they can explore regional differences in the occurrence of discriminatory experiences as well as the conditions under which particular aspects of discrimination are more or less likely to affect levels of adiposity. Future research may also benefit from both qualitative and quantitative methods to capture an individual's physiological or psychological responses to interpersonal discrimination $(7,19)$. Finally, studies on this topic should be internationalized or expanded to other countries around the world, since $80 \%$ of those found in this systematic review were carried out in the US.

Strengths and limitations

The strengths of this review include the use of ten bibliographic databases and electronic collections from the fields of psychology, social sciences, public health, 
nutrition and other important areas for the topic of interest. In addition, experts were contacted through electronic messages to find unpublished studies or papers with restricted access. All markers of adiposity were included in the review, such as weight, BMI, WC, WHR, visceral and subcutaneous fat, overweight and obesity to clarify the association between discrimination and adiposity, regardless of how the outcome was measured. However, only data on weight, BMI and WC were found among the included papers. Another strength of this review was obtaining information on potential confounders investigated in the original studies.

Despite the strengths, this review has limitations. We did not perform a meta-analysis due to significant heterogeneity among studies; thus, one potential limitation was that the review did not show an overall measure of the associations between discrimination and adiposity. The potential impact of publication bias was not formally assessed through a funnel plot; notwithstanding, the results of this review were not affected by or were only minimally affected by publication bias, since both published and grey literature had been thoroughly searched.

\section{Conclusion}

This review aimed to fill the gap in the literature about the consistency of the association between interpersonal discrimination and markers of adiposity. Despite the fact that a meta-analysis was not possible, this review provides evidence that selfreported discrimination can play an important role on weight, BMI and WC change. To strengthen this statement, the few results indicating inverse associations between discrimination and nutritional health were not statistically significant.

\section{References}

1. Fredrickson GM. Racism: A Short History: Scribe Publications; 2002. 207 p. 
2. Dovidio JF, Hewstone M, Glick P, Esses VM. Prejudice, stereotyping and discrimination: theoretical and empirical overview. In: Dovidio JF HM, Glick P, Esses VM., editor. The SAGE handbook of prejudice, stereotyping and discrimination London: SAGE; 2010. p. 3-28.

3. Blank RM, Dabady M, Citro CF. Measuring racial discrimination: panel on methods for assessing discrimination. Washington: The National Academies Press; 2004.

4. Krieger N. Discrimination and health inequities. Int J Health Serv 2014; 44/4:643710.

5. Paradies Y. A systematic review of empirical research on self-reported racism and health. Int J Epidemiol 2006;35/4:888-901.

6. Pascoe EA, Smart Richman L. Perceived discrimination and health: A meta-analytic review. Psychol Bull 2009;135/4:531-54.

7. Williams D, Mohammed S. Discrimination and racial disparities in health: evidence and needed research. J Behav Med 2009;32/1:20-47.

8. Goto JB, Couto PFM, Bastos JL. Systematic review of epidemiological studies on interpersonal discrimination and mental health. Cad Saude Publica 2013;29:445-59.

9. Williams DR, Neighbors HW, Jackson JS. Racial/ethnic discrimination and health: findings from community studies. Am J Public Health 2003;93/2:200-8.

10. Brown C, Matthews KA, Bromberger JT, Chang Y. The relation between perceived unfair treatment and blood pressure in a racially/ethnically diverse sample of women. Am J Epidemiol 2006;164/3:257-62.

11. Cozier Y, Palmer JR, Horton NJ, Fredman L, Wise LA, Rosenberg L. Racial discrimination and the incidence of hypertension in US black women. Ann Epidemiol 2006;16/9:681-7.

12. Roberts CB, Vines AI, Kaufman JS, James SA. Cross-sectional association between perceived discrimination and hypertension in African-American men and women: The Pitt County Study. Am J Epidemiol 2008;167/5:624-32.

13. Vines AI, Baird DD, Stevens J, Hertz-Picciotto I, Light KC, McNeilly M. Associations of abdominal fat with perceived racism and passive emotional responses to racism in African American women. Am J Public Health 2007;97/3:526-30. 
14. Hunte HER, Williams DR. The association between perceived discrimination and obesity in a population-based multiracial and multiethnic adult sample. Am J Public Health 2009;99/7:1285-92.

15. Shelton RC, Puleo E, Bennett GG, McNeill LH, Sorensen G, Emmons KM. The association between racial and gender discrimination and body mass index among residents living in lower-income housing. Ethn Dis 2009;19/3:251-7.

16. Lewis TT, Kravitz HM, Janssen I, Powell LH. Self-reported experiences of discrimination and visceral fat in middle-aged African-American and caucasian women. Am J Epidemiol 2011;173/11:1223-31.

17. Hickson DA, Lewis TT, Liu J, et al. The associations of multiple dimensions of discrimination and abdominal fat in African American adults: The Jackson Heart Study. Ann Behav Med 2012;43/1:4-14.

18. McCubbin LD, Antonio M. Discrimination and obesity among Native Hawaiians. Hawaii J Med Public Health 2012;71/12:346-52.

19. Krieger N. Discrimination and health. In: Berkman LFK, I., editor. Social epidemiology. New York: Oxford University Press; 2000. p. 36-75.

20. Williams DR, Neighbors H. Racism, discrimination and hypertension: evidence and needed research. Ethn Dis 2001;11/4:800-16.

21. Brondolo E, Rieppi R, Kelly K, Gerin W. Perceived racism and blood pressure: A review of the literature and conceptual and methodological critique. Ann Behav Med 2003;25/1:55-65.

22. Harrell JP, Hall S, Taliaferro J. Physiological responses to racism and discrimination: an assessment of the evidence. Am J Public Health 2003;93/2:243-8.

23. Gee GC, Ro A, Shariff-Marco S, Chae D. Racial discrimination and health among Asian Americans: evidence, assessment, and directions for future research. Epidemiol Rev 2009;31:130-51.

24. Dolezsar CM, McGrath JJ, Herzig AJ, Miller SB. Perceived racial discrimination and hypertension: a comprehensive systematic review. Health Psychol 2014;33/1:20-34.

25. Lewis TT, Williams DR, Tamene M, Clark CR. Self-reported experiences of discrimination and cardiovascular disease. Curr Cardiovasc Risk Rep 2014;8/1:1-15.

26. Couto PF, Goto JB, Bastos JL. Blood pressure and interpersonal discrimination: systematic review of epidemiologic studies. Arq Bras Cardiol 2012;99/4:956-63. 
27. Wyatt SB, Williams DR, Calvin R, Henderson FC, Walker ER, Winters K. Racism and cardiovascular disease in African Americans. Am J Med Sci 2003;325/6:315-31.

28. Cuffee YL, Hargraves JL, Allison J. Exploring the association between reported discrimination and hypertension among African Americans: a systematic review. Ethn Dis 2011;22/4:422-31.

29. Brondolo E, Love EE, Pencille M, Schoenthaler A, Ogedegbe G. Racism and hypertension: A review of the empirical evidence and implications for clinical practice. Am J Hypertens 2011;24/5:518-29.

30. Spahlholz J, Baer N, Konig HH, Riedel-Heller SG, Luck-Sikorski C. Obesity and discrimination - a systematic review and meta-analysis of observational studies. Obes Rev 2016;17/1:43-55.

31. Tull SE, Wickramasuriya T, Taylor J, et al. Relationship of internalized racism to abdominal obesity and blood pressure in Afro-Caribbean women. J Natl Med Assoc 1999;91/8:447-52.

32. Butler C, Tull ES, Chambers EC, Taylor J. Internalized racism, body fat distribution, and abnormal fasting glucose among African-Caribbean women in Dominica, West Indies. J Natl Med Assoc 2002;94/3:143-8.

33. Chambers EC, Tull ES, Fraser HS, Mutunhu NR, Sobers N, Niles E. The relationship of internalized racism to body fat distribution and insulin resistance among African adolescent youth. J Natl Med Assoc 2004;96/12:1594-8.

34. Lloyd CE, Wing RR, Orchard TJ. Waist to hip ratio and psychosocial factors in adults with insulin-dependent diabetes mellitus: The Pittsburgh epidemiology of diabetes complications study. Metabolism 1996;45/2:268-72.

35. Bell RA, Summerson JH, Summerson JH, Konen JC. Body fat, fat distribution, and psychosocial factors among patients with type 2 diabetes mellitus. Behav Med 1998;24/3:138-43.

36. Gee GC, Ro A, Gavin A, Takeuchi DT. Disentangling the effects of racial and weight discrimination on body mass index and obesity among Asian Americans. American journal of public health. Am J Public Health 2008;98/3:493-500.

37. Puhl RM, Andreyeva T, Brownell KD. Perceptions of weight discrimination: Prevalence and comparison to race and gender discrimination in America. Int $\mathbf{J}$ Obes 2008;32/6:992-1000. 
38. Andreyeva T, Puhl RM, Brownell KD. Changes in perceived weight discrimination among Americans, 1995-1996 through 2004-2006. Obes 2008; 16/5:1129-34.

39. BS. The Brain on Stress: Toward an Integrative Approach to Brain, Body and Behavior. Perspect Psychol Sci 2013;8/6:673-5.

40. Clark R, Anderson NB, Clark VR, Williams DR. Racism as a stressor for African Americans. A biopsychosocial model. Am Psychol 1999;54/10:805-16.

41. Pascoe EA, Richman LS. Effect of discrimination on food decisions. Self Identity 2011;10/3:396-406.

42. Gibbons FX, O'Hara RE, Stock ML, Gerrard M, Weng CY, Wills TA. The erosive effects of racism: reduced self-control mediates the relation between perceived racial discrimination and substance use in African American adolescents. J Pers Soc Psychol 2012;102/5:1089-104.

43. Twenge JM, Catanese KR, Baumeister RF. Social exclusion causes self-defeating behavior. J Pers Soc Psychol 2002;83/3:606-15.

44. Sutin A, Robinson E, Daly M, Terraciano A. Weight discrimination and unhealthy eating-related behaviors. Appetite 2016;102:83-9.

45. Harrell SP. A multidimensional conceptualization of racism-related stress: implications for the well-being of people of color. Am J Orthopsychiatry 2000;70/1:4257.

46. Shorter-Gooden K. Multiple Resistance Strategies: How African American Women Cope with Racism and Sexism. J Black Psychol 2004;30/3:406-25.

47. Almeida L, Savoy S, Boxer P. The role of weight stigmatization in cumulative risk for binge eating. J Clin Psychol 2011;67/3:278-92.

48. Dutton GR, Lewis TT, Durant N, et al. Perceived weight discrimination in the CARDIA study: Differences by race, sex, and weight status. Obes 2014;22/2:530-6.

49. McDonald JA, Terry MB, Tehranifar P. Racial and gender discrimination, early life factors, and chronic physical health conditions in midlife. Womens Health Issues 2014;24/1:e53-e9.

50. Mereish EH. The weight of discrimination: The relationship between heterosexist discrimination and obesity among lesbian women. Psychol Sex Orientat Gend Divers 2014;1/4:356-60. 
51. Jackson SE, Steptoe A, Beeken RJ, Croker H, Wardle J. Perceived weight discrimination in England: a population-based study of adults aged 50 years. Int $\mathbf{J}$ Obes 2015;39/5:858-64.

52. Tomfohr LM, Pung MA, Dimsdal JE. Mediators of the relationship between race and allostatic load in African and White American. Health Psychol 2016; 35/4:322-32.

53. Reid AE, Rosenthal L, Earnshaw VA, et al. Discrimination and excessive weight gain during pregnancy among Black and Latinayoung women. Soc Sci Med 2016;156:134-41.

54. Hankivsky O. Women's health, men's health, and gender and health: implications of intersectionality. Soc Sci Med 2012;74/11:1712-20.

55. Moher D, Shamseer L, Clarke M, et al. Preferred reporting items for systematic review and meta-analysis protocols (PRISMA-P) 2015 statement. Systematic Reviews 2015,4:1.

56. Reuters T. Endnote X5. New York: Thomson Reuters; 2011.

57. Hansson LM, Rasmussen F. Association between perceived health care stigmatization and BMI change. Obes Facts 2014;7:211-20.

58. Rosenthal L, Earnshaw VA, Carrol-Scott A, Henderson KE, Peters SM, McCaslin $\mathrm{C}$, Ickovics JR. Weight- and race-based bullying: health associations among urban adolescents. J Health Psychol 2015;20/4:401-12.

59. Cozier YC, Wise LA, Palmer JR, Rosenberg L. Perceived Racism in Relation to Weight Change in the Black Women's Health Study. Ann Epidemiol 2009;19/6:379-87.

60. Hunte HER. Association between perceived interpersonal everyday discrimination and waist circumference over a 9-year period in the midlife development in the United States cohort study. Am J Epidemiol 2011;173/11:1232-9.

61. Cunningham TJ, Berkman LF, Kawachi I, n. Changes in waist circumference and body mass index in the US Cardia cohort: Fixed-effects associations with self-reported experiences of racial/ethnic discrimination. J Biosoc Sci 2013;45/2:267-78.

62. Sutin AR, Terracciano A. Perceived Weight Discrimination and Obesity. PloS One. 2013;8/7:e70048.

63. Cozier YC, Yu J, Coogan PF, Bethea TN, Rosenberg L, Palmer JR. Racism, segregation, and risk of obesity in the Black Women's Health Study. Am J Epidemiol 2014;179/7:875-83. 
64. Jackson SE, Beeken RJ, Wardle J. Perceived weight discrimination and changes in weight, waist circumference, and weight status. Obes 2014;22:2485-88.

65. Sutin AR, Stephan Y, Grzywacz JG, Robinson E, Daly M, Terracciano A. Perceived weight discrimination, changes in health, and daily stressors. Obes 2016;24/10:2202-9.

66. Udo T, Grilo CM. Perceived weight discrimination, childhood maltreatment, and weight gain in U.S. adults with overweight/obesity. Obes 2016;24/6:1366-72.

67. Kressin NR, Raymond KL, Manze M. Perceptions of race/ethnicity-based discrimination: a review of measures and evaluation of their usefulness for the health care setting. J Health Care Poor Underserved 2008;19/3:697-730.

This article is protected by copyright. All rights reserved. 
Figure 1. Flow chart of the systematic review on the association between interpersonal discrimination and markers of nutritional status. 2015.
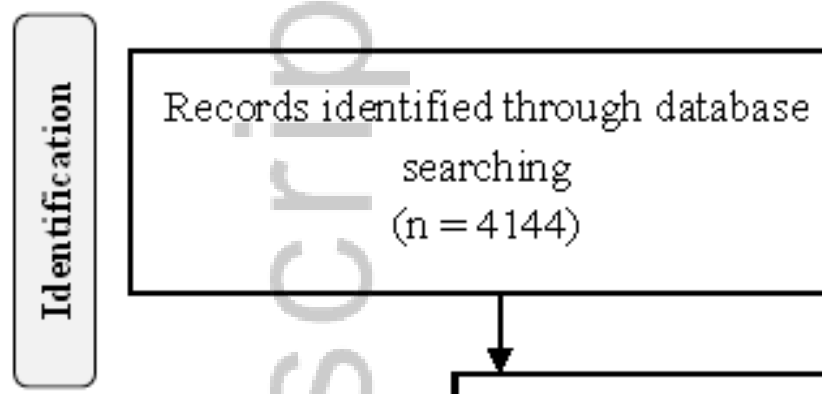

Additional records identified through other sources

$$
(\mathrm{n}=15)
$$
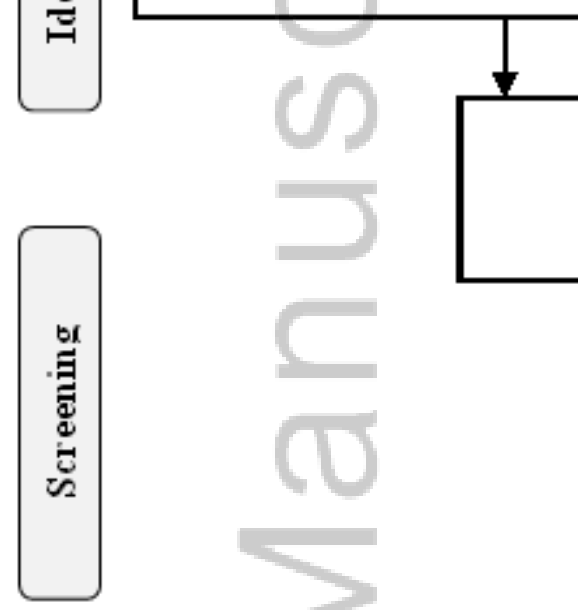

Records after duplicates removed

$(\mathrm{n}=2984)$
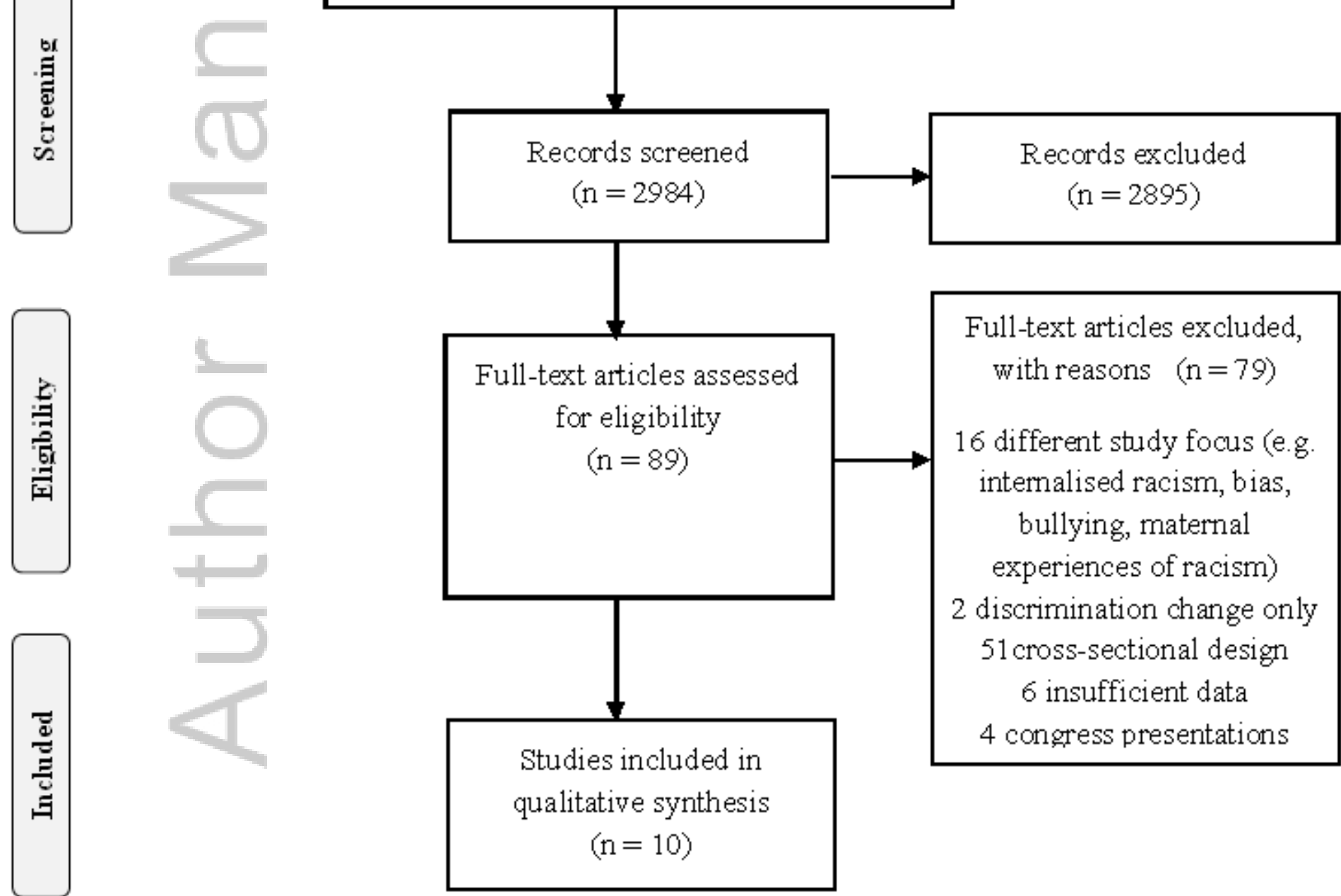

Full-text articles excluded, with reasons $(n=79)$

16 different study focus (e.g intemalised racism, bias, bullying, maternal experiences of racism)

2 discrimination change only 51 cross-sectional design 6 insufficient data 4 coneress presentations

OBR_12564_F1.tif 


\section{University Library}

\section{- M M I N E R VA A gateway to Melbourne's research publications}

Minerva Access is the Institutional Repository of The University of Melbourne

Author/s:

Bernardo, CDO;Bastos, JL;Gonzalez-Chica, DA;Peres, MA;Paradies, YC

Title:

Interpersonal discrimination and markers of adiposity in longitudinal studies: a systematic review

Date:

2017-09-01

Citation:

Bernardo, C. D. O., Bastos, J. L., Gonzalez-Chica, D. A., Peres, M. A. \& Paradies, Y. C. (2017). Interpersonal discrimination and markers of adiposity in longitudinal studies: a systematic review. OBESITY REVIEWS, 18 (9), pp.1040-1049. https://doi.org/10.1111/ obr.12564.

Persistent Link:

http://hdl.handle.net/11343/292964 